\title{
Computerized Accounting Systems: Measuring Structural Characteristics
}

\author{
Akamanwam Effiong Itang \\ Doctoral Candidate, LIGS University, Honolulu, Hawaii, USA
}

\begin{abstract}
This study aimed to develop a standard measurement tool for the effective assessment of computerized accounting systems (CAS) quality and effectiveness based on systems theory, in terms of their structural characteristics or functional components. The researcher identified five structural characteristics (components or subsystems) of CAS, namely internal controls, automated data-processing, relational database, automated reporting, and enhancing technologies components. The operationalization of these structural characteristics resulted in a 25 -item index that forms the measurement tool developed. The 25 -item index was constructed based on the review of prior literature to ensure content validity. The CAS measurement tool was administered to 384 active members of the Institute of Chartered Accountants of Nigeria (ICAN) through an online survey, and 234 useful responses were collected and analyzed to test the validity and reliability of the measurement tool. The researcher assessed the construct validity of the CAS measurement developed using the exploratory factor analysis, and the internal and external reliability using the Cronbach's alpha test of consistency and test-retest statistics, respectively. The results of the study suggest that the CAS measurement tool developed has strong content and construct validity as well as high internal and external reliability. It is, therefore, believed that the tool would yield valid and reliable results when employed in the assessment of computerized accounting systems. The study is significant as it introduces a new approach to assessing the quality of accounting information systems in terms of their structural characteristics instead of qualitative characteristics such as perceived advantages and ease-of-use of the systems. Further research is suggested to confirm the validity and reliability of the CAS measurement tool presented in this study.

Keywords: Accounting information systems, Automated data-processing, Automated reporting, Computerized accounting systems, Enhnacing technologies, Functional components, Internal controls, Relational database,
\end{abstract} Structural characteristics, Systems theory

DOI: $10.7176 /$ RJFA/11-16-05

Publication date:August $31^{\text {st }} 2020$

\section{Introduction}

The American Institute of Certified Public Accountants (AICPA) posits that Accounting, itself, is an information system used to effectively manage the economic activities of an entity (IACPA, 1966). In today's digital age and technology-based environment, this information system (Accounting) has gradually transited from manual to computerized or technology-based processes. Hence, Hurt (2013, pp. 4) defines the accounting information system as "a set of interrelated activities, documents, and technologies designed to collect data, process it, and report information to a diverse group of internal and external decision-makers in organizations." Accounting can, therefore, only be adequate and more efficient when practiced in computerized and technology-enhanced environments. Computerized accounting systems (CAS), which involve the application of computers and related technologies, schemes, and methods in the accounting function and process, have emerged to help overcome the drawbacks of manual accounting systems.

Following the increased adoption of computerized accounting systems by organizations worldwide, there have been several discussions and research on the usage and effectiveness of the systems in recent times. However, existing studies on the assessment or evaluation of computerized accounting systems (or accounting information systems) have focused only on their qualitative characteristics. Such qualitative characteristics of CAS include integration, speed, accuracy, timeliness, information scope, and ease of use (Choe, 1998; Doll and Torkzadeh, 1988; Meiryani, Susanto, and Sudrajat, 2019). The focus on qualitative characteristics could be explained by the fact that these characteristics are based on the perceived advantages and usefulness of accounting information systems. However, none of these qualitative characteristics could comprehensively assess the quality or effectiveness of CAS, as they only emphasize the importance and usefulness of the systems, which are but resultant effects of the systems' functionalities and processes. A more effective scheme for assessing the quality and effectiveness of CAS would be one that considers the features and operations inherent in the accounting systems than those that focus on the advantages and perceived usefulness of the systems. The need to use the functional components in the assessment of the accounting information systems arises from the fact that the components work in synergy towards optimizing the holistic goals of the systems. The objective of this study is, therefore, to develop and validate a measurement tool for assessing the quality and effectiveness of computerized accounting systems based on their structural characteristics (or functional components). 
The study aims, primarily, to contribute to improving the assessment or evaluation of the quality and effectiveness of computerized accounting systems. To achieve this, the researcher, based on systems theory, operationalized the structural characteristics of computerized accounting systems in terms of the systems' internal controls, automated data-processing, relational database, automated reporting, and the enhancing technologies components (or subsystems). A measurement tool comprising of a 25 -item index was, therefore, constructed to examine the quality and effectiveness of computerized accounting systems based on each of the structural characteristics and in combination. To test the internal validity, inter-rater, and internal consistency of the multiple-item measurement tool, the researcher administered it to a sample of 384 Chartered Accountants randomly selected from a population of all active members of the Institute of Chartered Accountants of Nigeria (ICAN). This sample size was selected based on the Krejcie and Morgan (1990) sample size determination table. The results of the study indicate that the measurement tool has a high level of validity and reliability, and therefore, could be employed in assessing the quality and effectiveness of computerized accounting systems.

The present study contributes to the literature and body of knowledge in accounting information systems in various ways. First, the study presents a comprehensive measurement tool to enable the assessment of the quality and effectiveness of CAS based on systems theory instead of perceived advantages. Second, this measurement tool helps overcome the validity and reliability issues associated with measurement scales and methods previously employed by researchers in evaluating the quality and effectiveness of accounting information systems generally.

The remaining part of this paper is organized into four different sections. Section 2 presents a review of the literature on the assessment of accounting information systems, system theory, and the conceptualization of structural characteristics of computerized accounting systems. Section 3 discusses the methods employed in the study, and Section 4 presents details on the quality assessment and empirical validation of the CAS measurement tool. Finally, Section 5 presents the conclusion and discussions of the study findings.

\section{Literature Review}

2.1 Computerized Accounting Systems (CAS)

An accounting information system is designed to collect, record, store, and process financial data as well as produce information for decision-makers (Romney \& Steinbart, 2006). Hurt (2013, p. 4) defines an accounting information system as "a set of interrelated activities, documents, and technologies designed to collect data, process it, and report information to a diverse group of internal and external decision-makers in organizations." The definition by Hurt (2013) incorporates technological tools as an aspect of the accounting information system, which points to the move from manual to computerized systems. Computerized accounting systems, therefore, involves the application of computers and related technologies in the collection, recording, storing and processing of financial data, and interpreting and reporting financial information to stakeholders (Marivic, 2009; Amidu et al., 2011). Al-joubory (2007), while exploring the impact of information technology on accounting information systems, identified significant components of an accounting information system to include accounting processing system and accounting reporting systems, which are characterized by functional automation and progress integration. Thanks to drastic changes in accounting systems infrastructure and functionalities, and the transformation in the financial information reporting model. Computerized accounting systems have significantly impacted positively on the accounting function of organizations in terms of enhanced information flow, employee performance, and financial reporting (Ismail and King, 2007; Sajady, Dastgir, and Hashem, 2008).

\subsection{Assessment of Computerized Accounting Systems Quality}

The primary goal of every accounting system is to provide financial information that is useful for decisionmaking purposes (Elliott and Elliott, 2013), and this goal can be only achievable if the accounting system in use is of good quality and effective. Therefore, it is imperative to ensure that the implemented computerized accounting system possesses the right features to yield the optimal results in terms of high-quality financial information presentation. Attempts are, therefore, made to assess the quality or effectiveness of computerized accounting systems (or accounting information systems) by prior studies. However, these existing studies have focused mainly on the qualitative characteristics of the system in their assessment. Most of these qualitative characteristics employed in assessing the effectiveness of accounting information systems utilize the Davis (1989) Technology Acceptance Model (TAM) and the Delone and McLean (1992, 2003) Information System Success Model (ISSM). The TAM is used to predict users' acceptance of information technology tools in terms of their perceived usefulness and ease of use, which are suitable for evaluating the willingness of users within an organization to accept, or the readiness of an organization to adopt and implement, a given technology tool (Davis, 1989; Davis and Venkatesh, 1996). On the contrary, several studies have used perceived usefulness and ease of use to measure the effectiveness of accounting information systems. The ISSM was developed based on the review and consolidation of various measures that had been employed in different information system studies 
between 1981-1987. It measures the success of an information system based on six major dimensions, namely system quality, information quality, use, user satisfaction, individual impact, and organizational impact (Delone and McLean, 1992). Of the six dimensions of ISSM, the system quality dimension, very significant as it is expected to measure the effectiveness of the system itself. The model evaluates system quality using eighteen measures as follows (Delone and McLean, 1992):

i. Data accuracy

ii. Data currency

iii. Database content

iv. Ease of use

v. Ease of learning

vi. Convenience of access

vii. Human factors

viii. Realization of user requirement

ix. The usefulness of system features and functions

x. System accuracy

xi. System flexibility

xii. System reliability

xiii. System sophistication

xiv. Systems integration

$\mathrm{xv}$. System efficiency

xvi. Resource utilization

xvii. Response time

xviii. Turnaround time

The above-listed measures of system quality indicated by the Delone and McLean's (1992, 2003) ISSM all relate to the perceived advantages of the information system, which are qualitative. None of the measures relate to the system's architectural features, components, or subsystems that should be the primary determinants of system quality. Qualitative characteristics are only indicators of good quality or effectiveness of the system and not the determinants of good quality. With the focus of the ISSM, studies on the quality or effectiveness of accounting information systems employ qualitative characteristics in their assessment. Meiryani, Susanto, and Sudrajat (2019) in their research on the effect of environmental complexity on the quality of accounting information systems (AIS) measured AIS quality in terms of integration, flexibility, and accessibility dimensions, which are part of the measures under the system quality dimension of Delone and McLean's (2003) model. In a study titled "Organizational Factors and Quality of Accounting Information Systems in Vietnam", Thuan and Huong (2019) also employed some of the ISSM measures such as ease of use, reliability, flexibility, among other criteria.

Whittington and Pany (2004) deviates from the TAM and ISSM models as they describe an efficient accounting information system in terms of task-oriented measures such as identification, valuation, recording, and processing of transactions, periodicity, and reporting. Though an assessment scheme with these factors reflects the essential stages in the accounting process, it does not consider the architecture of the accounting system that defines the various components and functionalities responsible for the effective execution of each of the stages in the accounting process. Therefore, such a scheme may not be an effective method of evaluation. Chang and King (2005) also developed a measuring tool for information systems performance based on the theoretical input-output model that emphasized the functional role of information systems in supporting the effectiveness of business processes and organizational performance. Their measurement tool, information systems functional scorecard (ISFS), consists of three output dimensions, namely systems performance, information effectiveness, and service performance. However, these indicated three dimensions of ISFS are output-oriented and not based on systems structure or components.

Table 1 presents a non-exhaustive summary of models or tools used in prior studies to assess the quality of accounting information systems.

\subsection{Systems Theory}

The general systems theory introduced by Bertalanffy in the 1930s defines a system as "a set of elements standing in interrelation among themselves and with the environment" (Bertalanffy, 1972, p. 417). The above definition suggests that every system comprises of components (or subsystems) that are interrelated, and which perform their functions towards the achievement of the objectives of the entire system. The systems theory deals with the interaction and relationships between the various parts of an entity, such that the sum of the parts is considered more than the system itself (Mele, Pels and Polese, 2010). Hence, the outcome of a system depends on the synergy between its various components or subsystems. As indicated by Ramosaj and Berisha (2014), systems theory is useful in studying phenomena with complex variables and understanding of how those 
variables relate and influence one another towards achieving the holistic goal of the system. Therefore, the performance of any computerized accounting system would depend on the effectiveness of its components individually and in combination.

Based on the systems theory, this study develops and validates a model for measuring how the compelling interplay of the various parts of a computerized accounting system enhances the fulfillment of the system's goals.

Table 1. Overview of Models and Tools to Assess Accounting Information Systems

\begin{tabular}{|c|c|c|c|c|}
\hline Models/tools & Author & Description & Remarks & $\begin{array}{c}\text { Examples of } \\
\text { studies } \\
\text { applied } \\
\end{array}$ \\
\hline $\begin{array}{l}\text { Technology } \\
\text { acceptance model } \\
\text { (TAM) }\end{array}$ & $\begin{array}{lr}\text { Davis } & (1989) ; \\
\text { Davis } & \text { and } \\
\text { Venkatesh } & (1996)\end{array}$ & $\begin{array}{l}\text { Predicts users' } \\
\text { acceptance and } \\
\text { organizations' } \\
\text { readiness to adopt } \\
\text { IT tools }\end{array}$ & $\begin{array}{l}\text { Based on perceived } \\
\text { usefulness and ease-of-use } \\
\text { instead of functional } \\
\text { components }\end{array}$ & $\begin{array}{l}\text { Whittington } \\
\text { and Pany } \\
(2004)\end{array}$ \\
\hline $\begin{array}{l}\text { Information } \\
\text { systems success } \\
\text { model (ISSM) }\end{array}$ & $\begin{array}{l}\text { DeLone } \\
\text { McLean } \\
\text { 2003) }\end{array}$ & $\begin{array}{l}\text { Measures success } \\
\text { of information } \\
\text { system (IS) based } \\
\text { on six dimensions } \\
\text { instead of systems } \\
\text { theory }\end{array}$ & $\begin{array}{l}\text { Its system quality } \\
\text { dimension is based on the } \\
\text { perceived advantages of } \\
\text { IS. }\end{array}$ & $\begin{array}{l}\text { Meiryani et } \\
\text { al., (2019); } \\
\text { Thuan and } \\
\text { Huong } \\
(2019)\end{array}$ \\
\hline $\begin{array}{l}\text { Information } \\
\text { systems functional } \\
\text { scorecard (ISFS) }\end{array}$ & $\begin{array}{l}\text { Chang and King } \\
(2005)\end{array}$ & $\begin{array}{l}\text { Is based on a } \\
\text { theoretical input- } \\
\text { output model }\end{array}$ & $\begin{array}{l}\text { Measures systems } \\
\text { performance, information } \\
\text { effectiveness, and service } \\
\text { performance }\end{array}$ & \\
\hline
\end{tabular}

Source: Exploratory Review of Literature

\subsection{Conceptualizing the Structural Characteristics of Computerized Accounting Systems}

In line with the systems theory, a computerized accounting system is a consolidation of various components or subsystems. These components form the architectural framework of the system that represents its structural characteristics. Software architecture defines the logical organization of software into multiple elements to enhance system performance and reliability (Paganini, 2019). Accounting information systems consist of integrated components such as hardware, software, brain-ware, databases, network technologies, and processes (McLeod \& Schell, 2006; Romney and Steinbart, 2009). Components of the accounting systems also include inputs, processes, outputs, storage, and internal controls (Hurt, 2013; Surendar and Rathnakar, 2019).

Considering the impact of information technology on accounting information systems, Al-joubory (2007) identified significant components of an accounting information system to include accounting processing and accounting reporting systems, which have become sophisticated through functional automation and process integration. In line with this position, Anggraeni (2016) indicated that one of the significant features of computerized accounting systems is process integration, which is the ability of the system to coordinate its various parts to perform several processes simultaneously. The common ground identified in the diverse views discussed above is that accounting information systems possess integrated components with interrelated functionalities. However, in line with the principles of garbage-in-garbage-out, the quality of outputs would depend on the inputs to the system. The system with the worst input cannot generate any good quality output. Hence, in this study, inputs and outputs were not considered as components of computerized accounting systems, while computer hardware and other related technologies were classified as enhancing technologies. The researcher, therefore, conceptualizes the structural characteristics of computerized accounting systems in terms of internal control component, automated data-processing component, relational database component, automated reporting component, and enhancing technologies.

2.4.1 Internal Controls Component

The Committee of Sponsoring Organizations of the Treadway Commission (COSO) defines internal control as "a process effected by an entity's board of directors, management, and other personnel, designed to provide reasonable assurance regarding the achievement of objectives relating to operations, reporting, and compliance" (COSO, 2013, pp. 3). The three primary strategic functions of an organization identified in COSO's definition of internal control are operations, reporting, and compliance. Hence, the primary aim of internal controls is to ensure the effectiveness of operations, good quality reporting on the operations, and proper compliance with policies, regulations, and laws. Computerized accounting systems should, therefore, possess inherent internal control functionalities that are executable throughout the input, process, storage, and output processes of the accounting system (Fardinal, 2013; Qatanani and Hezabr, 2015; Steckel, 2011). The internal controls component is, therefore, a very significant structural characteristic of the computerized accounting system (or accounting 
information system) as it enhances the integrity and effectiveness of the accounting process within the system and the performance of the entire system in general (Fardinal, 2013; Hurt, 2013).

2.4.2 Automated Data-processing Component

Computerized accounting systems are driven by software packages moduled on accounting principles and procedures, as well as business logic that enables the systems to perform accounting tasks and processes automatically (Hurt, 2013). The subsystem that is responsible for this function is referred to in this study as the automated data processing component. This component has been indicated for the accounting systems' overall seamless processing capacity and their ability to validate data, post transactions, balance accounts, and reconcile them without human intervention (Anggraeni, 2016; Hurt, 2013; Intuit Inc, 2018). As indicated by Aggraeni (2016), the automated capability of the computerized accounting system makes it possible for tasks such as capturing of financial data, posting of transactions, and balancing of accounts to be performed without human intervention and with higher speed and accuracy. Hence, the automated data-processing component is an essential structural characteristic of computerized accounting systems.

2.4.3 Relational Database Component

An accounting system, generally, deals with an extensive collection of data. The relational database component is the subsystem that is responsible for the storage, maintenance, and utilization of data in the computerized accounting system. As indicated by Agung (2015) and Ramakrishnan and Gehrke (2003), relational database management systems (RDBMS) handles the storage, maintenance, and utilization of data and information in an automated environment. Every computerized accounting system is characterized by a relational database management subsystem that maintains the relationship between various records and files stored in the system, thereby ensuring data independence, integrity, security, scalability, and concurrent access to data in the system (Agung, 2015; Ramakrishnan and Gehrke, 2003). If the RDBMS is not efficient, then the data processing and reporting functionalities of the system would be ineffective, thereby inhibiting the optimal performance of the entire accounting system. Hence, the relational database component stands to be an essential structural characteristic of the computerized accounting system.

2.4.4 Automated Reporting Component

A computerized accounting system is characterized by the ability to automatically generate outputs in the form of reports that are based on defined parameters and reporting options (Hurt, 2013; Intuit Inc, 2018). This automated reporting subsystem works in consonance with the relational database management subsystem for the retrieval and utilization of data and information relevant for every report (Intuit Inc, 2018; Sage Software, 2015; Ramakrishnan and Gehrke, 2003). The automated reporting component is, therefore, a very significant structural characteristic of the computerized accounting system as its inefficiency would jeopardize the strategic objective of the system, which is to provide decision-useful information to the various stakeholders.

2.4.5 Enhancing Technologies

The first four structural characteristics of computerized accounting systems discussed earlier (internal controls, automated data processing, relational database, and automated reporting components) are synthesized within the framework of the accounting software architecture, and logically organized to enhance the performance and reliability of the software (Paganini, 2019). However, these components and the entire system depend on some other technological tools for effective performance. These secondary technological tools on which the accounting system depends to function effectively are referred to in this study as enhancing technologies. These enhancing technologies include various computer hardware, firmware, applications, and accessories such as networking infrastructure, web and cloud technologies, printing and imaging equipment, among others (Amidu et al., 2011; Anggraeni, 2016; Ghasemi, Shafejepour, Aslani and Barvayeh, 2011; Gupta, Rewari, and Jain, 2017).

\section{Methods}

3.1 Study Design

The study employed the survey research design. This research design was adopted as it helps to provide explanations to study phenomenon, attitudes, and opinions, as well as provide study results that could be inferred on the entire study population (Salhin et al., 2016; Mathiyazhaga and Nandan, 2010; Collis and Hussey, 2014; Kpolovie, 2016).

\subsection{Study Population and Sample}

The active membership of the Institute of Chartered accountant of Nigeria (ICAN) constituted the population of the study. A sample of 384 members randomly selected for the study based on the Krejcie and Morgan (1970, p. 608) sample size determination table. ICAN members were chosen as the population of this study as they have proper knowledge accounting and experience in the use of diverse computerized accounting systems. 


\subsection{Operationalizing the Structural Characteristics of CAS}

In this study, the structural characteristics of computerized accounting systems are conceptualized in terms of internal controls component, automated data processing component, relational database component, automated reporting component, and enhancing technologies. This section presents how these components would be operationalized for effective measurement.

3.3.1 Internal Controls Component Operationalized

Several forms of internal controls are indicated by diverse authors, including Hurt (2013), Intuit Inc (2018), Itang (2017), Steckel (2011), and Zielinski (2015). For this study, the internal controls component of computerized accounting system is measured based on the following five indicators.

(i) Access control - the system configured to allow only predefined users to have access using unique usernames and passwords.

(ii) Segregation of duties - users' profiles defined with specific roles such that individual user only performs specific tasks assigned to them.

(iii)Accuracy checks - the ability of the system to check and confirm the accuracy of data entered in the system in terms of format, type, figures, duplication, and totals.

(iv)Security control - the ability of the system to safeguard data from intrusions, theft, and manipulation as well as protect the data against loss from contingency and disasters.

(v) Audit trails - the ability of the system to keep track of the activities of users and the transactions executed by each person.

3.3.2 Automated Data-processing Component Operationalized

Computerized accounting systems are also characterized by automated and seamless processing of data, data validation, posting of transactions, and balancing and reconciliation of accounts (Anggraeni, 2016; Hurt, 2013; Intuit Inc, 2018). Therefore, in this study, the automated data processing component of computerized accounting systems is measured in terms of the following five parameters:

(i) Seamless processing - the capacity the system to process data seamlessly without human intervention.

(ii) Data validation - the ability of the system to automatically validate data entered in the system for accuracy.

(iii)Transaction posting - the ability of the system to post financial transactions automatically.

(iv)Accounts balancing - the ability of the system to perform ledger accounts balancing procedures automatically.

(v) Accounts reconciliation - the ability of the system to reconcile individual accounts automatically.

3.3.3 Relational Database Component Operationalized

As indicated by Agung (2015) and Ramakrishnan and Gehrke (2003), computerized accounting systems have relational database management subsystems that enable the system to manage large collections of data in terms of storage, maintenance, retrieval, data independence, integrity, security, scalability, and concurrent access. In this study, the relational database component of the computerized accounting system is, therefore, measured based on the following five parameters:

(i) Large storage capacity - the capacity of the system to store a large collection of data.

(ii) Data maintenance and retrieval - the ability of the system to enhance seamless data update and retrieval.

(iii)Data independence and integrity - the ability of the system to ensure cannot be maliciously manipulated and that the completeness and accuracy of data are not compromised.

(iv)Data backup and recovery - the provision in the system for regular data backed up regularly and the capacity to enhance the recovery of data back to the system after a disaster.

(v) Scalability and concurrent access to data - the ability of the system to allow multiple users to have access to data or retrieve similar information from the system without obstruction and interference.

3.3.4 Automated Reporting Component Operationalized

Intuit Inc (2018) and Sage Software (2015) have indicated the various reporting capabilities of accounting software to include the ability to generate reports on various transactions and financial statements in several formats. Following from the positions of Intuit Inc (2018) and Sage Software (2015), the automated reporting component of the computerized accounting system is measured in this study on the following five parameters:

(i) Seamless reporting - the capacity of the system to generate reports seamlessly without human intervention.

(ii) Trial balance and General ledger (GL) reports - the ability of the system to generate the triable and various forms of GL and transaction reports.

(iii)Financial statements - the ability of the system to generate financial statements automatically.

(iv)Multi-format options - the ability to generate financial statements in multiple formats.

(v) Comparative reporting - the ability of the system to provide reports with comparative figures. 3.3.5 Enhancing Technologies Operationalized In line with works of Amidu et al. (2011), Anggraeni (2016), Ghasemi et al. (2011), and Gupta et al. (2017), this 
study measures the enhancing technologies to the computerized accounting system in terms of the following five indicators:

(i) Network configuration - the ability of the system to function on a network for use by multiple users.

(ii) Cloud computing - the system is cloud-based or can be migrated to the cloud.

(iii)Point of Sale (POS) interface - the ability of the system to interface with a POS device.

(iv)Document upload and attachments - the ability of the system to process source documents upload and attachments.

(v) Email and SMS interface - the ability of the system to interface with emailing and SMS applications.

\subsection{Development of the CAS Measurement Tool}

Based on the exploration of prior literature, five structural characteristics of computerized accounting systems were identified, namely, internal controls component, automated data-processing component, relational database component, automated reporting component, and enhancing technologies. To ensure the development of a reliable tool for measuring the quality of computerized accounting systems, each of the five functional components was operationalized based on five measurement criteria or parameters synthesized from existing literature, giving a total of twenty-five (25) measurement parameters. A 25-item index was, therefore, constructed to measure the robustness and quality of computerized accounting systems in terms of each of the structural characteristics individually and holistically. Each item was presented on a five-point Likert-type scale, with (1) representing 'Strongly Disagree' and (5) for 'Strongly Agree'.

\subsection{Administration of the CAS Measurement Tool}

The 25-item measurement tool was administrated through an online (web-based) questionnaire implemented on the SmartSurvey platform (www.smartsurvey.co.uk). The web-based instrument was necessary since the study was carried out amidst the global lockdown caused by the COVID-19 coronavirus pandemic during which personal contacts were not possible. Though it has been indicated that online surveys yield relatively lower responses than on-paper surveys (Nulty, 2008), the author made efforts to ensure good participation. As suggested by Collis and Hussey (2014), follow-up requests were sent to participants to ease the problem of questionnaire fatigue and non-response bias, and this helped to enhance the response rate to the survey. Two hundred and thirty-one (231) useful responses were obtained out of the 384 participants that were given access to the online questionnaire. The overall response rate of 60 percent was, therefore, achieved, which falls within the generally acceptable survey response rates of 50\%-80\% indicated by Baruch and Holtom (2008), and above the average response rates for online surveys reported by Nulty (2008).

\section{Quality Assessment and Empirical Checks on the CAS Measurement Tool}

4.1 Assessment of Quality of Operational Measures Employed

The author assessed the quality of the operational measures employed in the rating scales by first computing the standard scores on each of the five structural characteristics, namely internal controls, automated data-processing, relational database, automated reporting, and enhancing technologies. The total score for each of the components or structural characteristics was obtained by dividing the sum of the mean scores for each item by 5 (the number of items), and the overall mean score was then obtained by adding the total mean scores for each component and dividing by 5 (the number of components), thereby giving all the components equal weights. The score ranges between 1 (indicating a poor rating) and 5 (indicating an excellent rating). An overview of the scores on each of the 25 measurement items is presented in Table 2. From Table 2, each of the components has a score above 4.0, and the entire measurement scale has a score of 4.49. Therefore, individual components and the whole measurement scale have very strong scores, suggesting that the measures assigned to each of the constructs in the rating scale are appropriate. 
Table 2. Scores on operational measures utilized for the structural characteristics

\begin{tabular}{|c|c|c|c|c|c|c|}
\hline Items & Description & Mean & Std. Dev. & Min. & Median & Max. \\
\hline \multicolumn{7}{|c|}{ Internal controls } \\
\hline $\mathrm{IC} 1$ & Access control & 4.72 & 0.819 & 1 & 5.00 & 5 \\
\hline IC2 & Segregation of duties & 4.61 & 0.882 & 1 & 5.00 & 5 \\
\hline IC3 & Accuracy checks & 4.35 & 0.961 & 1 & 5.00 & 5 \\
\hline IC4 & Security control & 4.55 & 0.744 & 2 & 5.00 & 5 \\
\hline \multirow[t]{2}{*}{ IC5 } & Audit trail & 4.61 & 0.887 & 1 & 5.00 & 5 \\
\hline & Internal control total score & 4.57 & & & & \\
\hline \multicolumn{7}{|c|}{ Automated data processing } \\
\hline AD1 & Seamless processing & 4.61 & 0.794 & 1 & 5.00 & 5 \\
\hline $\mathrm{AD} 2$ & Data validation & 4.45 & 0.795 & 2 & 5.00 & 5 \\
\hline AD3 & Transaction posting & 4.29 & 1.193 & 1 & 5.00 & 5 \\
\hline AD4 & Accounts balancing & 4.53 & 0.883 & 2 & 5.00 & 5 \\
\hline \multirow[t]{2}{*}{ AD5 } & Accounts reconciliation & 4.22 & 0.927 & 2 & 4.00 & 5 \\
\hline & Auto. processing total score & 4.42 & & & & \\
\hline \multicolumn{7}{|c|}{ Relational database } \\
\hline RD1 & Large storage & 4.80 & 0.403 & 4 & 5.00 & 5 \\
\hline RD2 & Data maintenance & 4.74 & 0.439 & 4 & 5.00 & 5 \\
\hline RD3 & Data independence & 4.52 & 0.727 & 2 & 5.00 & 5 \\
\hline RD4 & Backup/recovery & 4.53 & 0.703 & 2 & 5.00 & 5 \\
\hline \multirow[t]{2}{*}{ RD5 } & Concurrent access & 4.59 & 0.710 & 1 & 5.00 & 5 \\
\hline & Relational Database total score & 4.64 & & & & \\
\hline \multicolumn{7}{|c|}{ Automated reporting } \\
\hline AR1 & Seamless reporting & 4.74 & 0.561 & 2 & 5.00 & 5 \\
\hline AR2 & Trial balance/GL reports & 4.82 & 0.446 & 2 & 5.00 & 5 \\
\hline AR3 & Financial statements & 4.27 & 0.945 & 2 & 5.00 & 5 \\
\hline AR4 & Multiple format options & 4.47 & 0.762 & 2 & 5.00 & 5 \\
\hline \multirow[t]{2}{*}{ AR5 } & Comparative reporting & 4.40 & 0.883 & 2 & 5.00 & 5 \\
\hline & Auto. reporting total score & 4.54 & & & & \\
\hline \multicolumn{7}{|c|}{ Enhancing technologies } \\
\hline ET1 & Network configuration & 4.58 & 0.741 & 3 & 5.00 & 5 \\
\hline ET2 & Cloud computing & 4.31 & 0.935 & 2 & 5.00 & 5 \\
\hline ET3 & POS interface & 4.00 & 1.181 & 1 & 5.00 & 5 \\
\hline ET4 & Document upload & 4.08 & 1.177 & 1 & 5.00 & 5 \\
\hline \multirow[t]{2}{*}{ ET5 } & Email/SMS interface & 4.35 & 0.896 & 2 & 5.00 & 5 \\
\hline & Enhancing tech. total score & 4.26 & & & & \\
\hline Overall 1 & I score & 4.49 & & & & \\
\hline
\end{tabular}

Source: Field Study (2020)

\subsection{Validity Checks}

The constructs employed in the measurement scale are based on prior literature, and this was to ensure the validity of the measurement scale. Validity checks reveal the degree to which measures employed in the measurement tool is collecting data that, actually, represent the concepts under investigation (Collis and Hussey, 2014). To ensure content validity, the measurement scale was subjected to a field test using ten (10) professional accountants who work in computerized accounting environments and have in-depth knowledge of accounting information systems. They were requested to comment on the clarity, relevance, and sufficiency of the items employed in the measurement tool. Their comments and suggestions were used to enhance the instrument's content validity. The instruments' construct validity was checked using exploratory factor analysis, which is a handy tool in assessing the relationship patterns that exist between variables or constructs and the factors inherent in each construct (William, Onsman and Brown, 2010; Child, 2006; Samuels, 2016). The results of the exploratory factor analysis (EFA) and the corresponding factor loadings are presented in Table 3 and Table 4. 
Table 3: Exploratory Factor Analysis for Computerized Accounting Systems Rating Scale

\begin{tabular}{llrr}
\hline \multicolumn{1}{c}{ Factor } & Eigenvalue & \% of Variance & Cumulative \% of Variance \\
\hline IC - Internal controls & & & \\
Factor 1 & 3.122 & 62.445 & 62.445 \\
Factor 2 & 0.983 & 19.655 & 82.100 \\
Factor 3 & 0.366 & 7.314 & 89.414 \\
Factor 4 & 0.356 & 7.115 & 96.529 \\
Factor 5 & 0.174 & 3.471 & 100.000 \\
\hline AP - Automated data-processing & & & \\
Factor 1 & 3.515 & 70.306 & 70.306 \\
Factor 2 & 0.680 & 13.602 & 83.908 \\
Factor 3 & 0.334 & 6.676 & 90.584 \\
Factor 4 & 0.236 & 4.728 & 95.312 \\
Factor 5 & 0.234 & 4.688 & 100.000 \\
RD - Relational database & & & \\
Factor 1 & 2.894 & 57.875 & 57.875 \\
Factor 2 & 1.325 & 26.491 & 84.367 \\
Factor 3 & 0.405 & 8.104 & 92.471 \\
Factor 4 & 0.331 & 6.623 & 99.094 \\
Factor 5 & 0.045 & 0.906 & 100.000 \\
\hline AR - Automated reporting & & & \\
Factor 1 & 2.999 & 59.971 & 59.971 \\
Factor 2 & 0.830 & 16.607 & 76.578 \\
Factor 3 & 0.511 & 10.224 & 86.802 \\
Factor 4 & 0.368 & 7.352 & 94.154 \\
Factor 5 & 0.292 & 5.846 & 100.000 \\
\hline ET - Enhancing technologies & & & \\
Factor 1 & 3.599 & 71.973 & 71.973 \\
Factor 2 & 0.542 & 10.833 & 82.806 \\
Factor 3 & 0.493 & 9.867 & 92.673 \\
Factor 4 & 0.232 & 4.648 & 97.320 \\
Factor 5 & $\mathbf{0 . 1 3 4}$ & $\mathbf{2 . 6 8 0}$ & $\mathbf{1 0 0 . 0 0 0}$ \\
\hline Sourc: Anlysi & &
\end{tabular}

Source: Analysis of Survey Data (2020)

Table 3 shows the Eigenvalue, percentage variance, and cumulative percentage variance of factors for the computerized accounting systems (CAS) rating scale. The internal control construct has one factor with Eigenvalues of 3.122, which is equal to or greater than 1 . The factor explained $62.445 \%$ of the variances in the dataset. The automated data-processing construct also has one factor with Eigenvalue of 3.515, which is equal to or greater than 1 . This factor accounted for $70.306 \%$ of the variances in the dataset. The relational database construct has two factors having Eigenvalues equal to or greater than 1, with eigenvalues of 2.916 and 1.347, respectively. These two factors accounted for $84.367 \%$ of the variances in the dataset. The automated reporting construct has one factor with Eigenvalue that is equal to or greater than 1, with 2.999 Eigenvalue, which accounted for $59.971 \%$ of the variances in the dataset. The last construct, enhancing technologies, also has one factor with Eigenvalue equal to or greater than 1. The Eigenvalue for this factor is 3.599, and this accounted for $71.973 \%$ of the variances in the dataset.

Kaiser (1960) maintained that all factors with Eigenvalues of 1.0 or above should be retained for a construct. Therefore, internal controls, automated data-processing, automated reporting, and enhancing technologies constructs had one factor each retained, while two factors were retained for the relational database construct. 
Table 4: EFA Rotated Factor Loadings for Computerized Accounting Systems Rating Scale

\begin{tabular}{|c|c|c|}
\hline \multirow[b]{2}{*}{ Items } & \multicolumn{2}{|r|}{ Factor loadings } \\
\hline & Factor 1 & Factor 2 \\
\hline \multicolumn{3}{|l|}{ IC - Internal controls } \\
\hline IC 1 - Access control & 0.823 & - \\
\hline IC 2 - Segregation of duties & 0.830 & - \\
\hline IC3 - Accuracy checks & 0.648 & - \\
\hline IC4 - Security control & 0.857 & - \\
\hline IC5 - Audit trail & 0.776 & - \\
\hline \multicolumn{3}{|l|}{ AP - Automated data-processing } \\
\hline AP1 - Seamless processing & 0.797 & - \\
\hline AP2 - Data validation & 0.885 & - \\
\hline AP3 - Transaction posting & 0.856 & - \\
\hline AP4 - Accounts balancing & 0.860 & - \\
\hline AP5 - Accounts reconciliation & 0.790 & - \\
\hline \multicolumn{3}{|l|}{ RD - Relational database } \\
\hline RD1 - Large storage & 0.163 & 0.898 \\
\hline RD2 - Data maintenance & 0.333 & 0.878 \\
\hline RD3 - Data independence & 0.956 & 0.349 \\
\hline RD4 - Backup and recovery & 0.960 & 0.314 \\
\hline RD5 - Concurrent access & 0.873 & 0.119 \\
\hline \multicolumn{3}{|l|}{ AR - Automated reporting } \\
\hline AR1 - Seamless reporting & 0.765 & - \\
\hline AR2 - Trial balance/GL reports & 0.750 & - \\
\hline AR3 - Financial statements & 0.797 & - \\
\hline AR4 - Multiple format options & 0.820 & - \\
\hline AR5 - Comparative reporting & 0.737 & - \\
\hline \multicolumn{3}{|l|}{ ET - Enhancing technologies } \\
\hline ET1 - Network configuration & 0.742 & - \\
\hline ET2 - Cloud computing & 0.793 & - \\
\hline ET3 - POS interface & 0.876 & - \\
\hline ET4 - Document upload & 0.931 & - \\
\hline ET5 - Email/SMS interface & 0.887 & - \\
\hline
\end{tabular}

Source: Analysis of Survey Data (2020)

Table 4 shows the factor loadings for the five items in each construct. Factor loadings represent the correlation coefficients between items in a construct and the factors they load on. As indicated by Muijs (2011), factor loadings closer to 1.0 or -1.0 show a strong correlation between a construct and the factor it loads on, while factor loadings closer to zero (0) suggests weak correlation. The general rule is that an item belongs to a factor if its loading on the factor is more than 0.30 or less than -0.30 . However, in line with Goldberg and Velicer (2006), only constructs with high factor loadings of 0.50 or above (and -0.50 or less) were considered in the study to ensure that the observed variable is more strongly related to the factor.

The items in the internal control construct, namely access control, segregation of duties, accuracy checks, security control, and audit trail, all load on factor 1 with factor loadings of $0.823,0.830,0.648,0.857$, and 0.776 , respectively. The result suggests that each of the items are strongly interrelated. For the automated dataprocessing construct, the five items (seamless processing, data validation, transaction posting, accounts balancing, and accounts reconciliation) all loading on one factor with factor loadings of $0.797,0.885,0.856$, $0.860,0.790$, respectively. This result suggests a strong interrelatedness between the five items. Relational database construct loads on two factors, with three items (data independence, backup and recovery, and concurrent access) loading on factor 1 with factor loadings of $0.956,0.960,0.873$, respectively; while two factors (large storage and data maintenance) load on factor 2 with factor loadings of 0.898 and 0.878 , respectively. This suggests that the items in the relational database construct are strongly interrelated, though not loading on one factor.

The five items in the automated reporting construct, namely seamless reporting, trial balance/GL account reports, financial statements, multiple format options, and comparative reporting, all loading on one factor with factor loadings of $0.765,0.750,0.797,0.820$, and 0.737 , respectively; which suggests that the five measures are interrelated. Enhancing technologies construct also has all five items (network configuration, cloud computing, POS interface, document upload, and Email/SMS interface) loading on one factor with factor loadings of 0.742 , $0.793,0.876,0.931$, and 0.887 , respectively. The result suggests the interrelatedness of the five items used in 
measuring enhancing technologies construct.

\subsection{Reliability Checks}

Gliem and Gliem (2003) indicated that when Likert-type scales are used in a research instrument, it becomes necessary to check for the reliability of the instrument. The 25 -item measurement scale was, therefore, checked for both internal and external reliability. The internal reliability of the instrument was checked using the Cronbach's Alpha test of consistency, while the external reliability was checked using the test-retest statistics. The Cronbach's alpha represents the average of the reliability coefficients obtainable for all possible combination of instrument items when shared into two halves, and requires a single test administration and its coefficient $(\alpha)$ ranges between 0 and 1 and that the closer the coefficient value is to 1.0 , the higher the internal reliability of the items in the rating scale (Gliem and Gliem, 2003). The result of the Cronbach's alpha, as obtained from the SPSS software output is shown in Table 5.

As shown in Table 5, the constructs on the computerized accounting systems (CAS) rating scale each have a high Cronbach's alpha coefficient $(\alpha)$ of $0.840,0.886,0.816,0.814$, and 0.898 , respectively. The overall (total item) Cronbach's alpha coefficient $(\alpha)$ for the CAS measurement scale is 0.947 . The result, therefore, indicates that all the scales in the research instrument have high internal consistency and acceptable level of reliability.

For the test-rest check, which involves administering two pilot tests to the same set of participants at two different intervals, twenty (20) professional accountants were given the instrument to complete twice with a period of 14 days in-between the two tests. Correlation analysis was then conducted on the mean scores for each of the items on the rating scale. The result of the test-retest analysis is presented in Table 6, which indicates that the two sets of pilot test data gave an extremely strong correlation coefficient of 0.992. Radhakrishna (2007) suggested that a coefficient of 0.70 or higher is considered an acceptable level of instrument reliability. Therefore, the result of the test-retest analysis indicates that the research instrument has an acceptable level of external reliability.

Table 5: Cronbach's Alpha - Internal Consistency Reliability Test

\begin{tabular}{|c|c|c|c|c|c|c|}
\hline Construct/Item & \multicolumn{2}{|c|}{ Item Cronbach's alpha ( $\left.{ }^{\alpha}\right)$} & \multicolumn{3}{|c|}{ Total item Cronbach's alpha ( ${ }^{(\alpha)}$} & Reliability \\
\hline CAS scale & & & \multicolumn{3}{|c|}{0.947} & High \\
\hline Internal controls & 0.840 & & & & & \\
\hline Automated data processing & 0.886 & & & & & \\
\hline Relational database & 0.816 & & & & & \\
\hline Automated reporting & 0.814 & & & & & \\
\hline Enhancing technologies & 0.898 & & & & & \\
\hline \multicolumn{7}{|c|}{ Source: Analysis of Survey data (2020) } \\
\hline \multicolumn{7}{|c|}{ Table 6: Test-Retest Reliability Statistics } \\
\hline Test-retest & Mean & Std. Deviat & & Items on Scale & \multicolumn{2}{|c|}{ Correlation } \\
\hline Test 1 mean score & 4.188 & 0.456 & & 25 & & \\
\hline Test 2 mean score & 4.240 & 0.445 & & 25 & \\
\hline Pearson Correlation (r) & & & & & \multicolumn{2}{|l|}{0.989} \\
\hline Sig. (2-tailed) & & & & & \multirow{2}{*}{\multicolumn{2}{|c|}{0.000}} \\
\hline No. of cases & & & & & & \\
\hline
\end{tabular}

Source: Analysis of Survey Data (2020)

\section{Conclusion and Discussions}

The study aimed to develop and validate a comprehensive measurement tool for the assessment of the quality and effectiveness of computerized accounting systems (CAS). Based on systems theory, the researcher, therefore, constructed a 25 -item index that could be used to evaluate the quality of computerized accounting systems in terms of their structural characteristics or functional components, namely internal controls, automated dataprocessing, relational database, automated reporting, and enhancing technologies components. The assessment of the quality of computerized accounting systems, as comprehensively as possible, is significant to the accounting profession and practice as it may help in the proper selection of an accounting system for adoption and implementation by an organization. It also ensures that value for money is obtained when investing in a computerized accounting system, that the perceived advantages and usefulness of an adopted system would be achieved, and that users' satisfaction in the system is maintained. Also, this study is significant because, by following the systems approach, the CAS measurement tool presented deviates from the traditional assessment approach that measures accounting information systems quality based on the qualitative characteristics such as perceived benefits and ease-of-use of accounting systems.

Extensive prior empirical literature and some instruments employed in previous related studies were extensively considered in developing the measurement tool for the assurance of construct validity. Descriptive 
statistics such as mean scores and standard deviation were also employed to assess the quality and appropriateness of the constructs used in the rating scales, which indicated a remarkably high score. The validity and reliability checks conducted on the 25-item index yielded acceptable results. To peer review of the instrument by ten (10) knowledgeable and experienced professional accountants assured the content validity of the measurement tool. At the same time, the result of the exploratory factor analysis gave very high factor loadings of 0.60 and above, indicating strong interrelatedness between the constructs on measurement index.

The computerized accounting systems measurement tool was also tested for internal and external reliability. The result of the Cronbach's alpha test of consistency indicates that individual items on the rating scale had coefficients between 0.814 and 0.898 , with an overall (total item) coefficient of 0.947 . The test-retest statistics for external reliability give a strong coefficient of 0.992 . The results of the Cronbach's alpha test and the testretest statistics, therefore, indicate that all individual measurement items and the overall measurement tool have high and acceptable levels of internal and external reliability.

Overall, the results of this study suggest that the component-based CAS measurement tool developed has strong content and construct validity, as well as a sufficiently high level of internal and external reliability. It is, therefore, believed that with the indicated results, the measurement tool would yield valid and reliable results when employed in the assessment of computerized accounting systems. Like every other measurement tool, the measurement tool presented in this study has its limitations. One of such limitations being the fact that the tool requires the raters' adequate knowledge of the computerized accounting system being assessed to yield optimal efficiency and effectiveness. Comparing the results of the CAS measurement tool presented in this study with the results of other measurement tools using the same sample may increase insights into its validity and reliability.

Finally, considering the study context and sample, further research using different settings and samples is required to confirm the validity and reliability of the CAS measurement tool indicated in this study. Such studies would also provide more insight into the evaluation of the quality of computerized accounting systems based on systems theory.

\section{References}

Al-joubory, A. A. (2007). Exploring the impact of information technology on AIS. Dirasat, Administrative Sciences, 34(2), 470-487.

Agung, M. (2015). Accounting information systems and improvement on financial reporting. International Journal of Recent Advances in Multidisciplinary Research, 2(11), 950-957.

American Institute of Certified Public Accountants (1996). AICPA professional standards: Code of professional conduct and bylaws as of June 1, 1996. AICPA Professional Standards - 116. Retrieved from https://egrove.olemiss.edu/aicpa prof/116

Amidu, M., Effah, J. \& Abor, J. (2011). E-Accounting practices among small and medium enterprises in Ghana. Journal of Management Policy \& Practice, 12(4), 146-155.

Anggraeni, A. F. (2016). Correlation between information technology and management information systems quality. International Journal of Scientific \& Technology Research, 5(6), 168-172.

Baruch, Y. \& Holtom, B. C. (2008). Survey response rate levels and trend in organizational research. Human Relations, 6(8), 1139-1160.

Bertalanffy, L. v. (1968). General systems theory: Foundations, development, applications. New York: George Braziller Inc.

Bertalanffy, L. v. (1972). The history and status of general systems theory. The Academy of Management Journal, 15(4), 407-426.

Chang, J. C., \& King, W. R. (2005). Measuring the performance of information systems: A functional scorecard. Journal of Management Information Systems, 22(1), 85-115.

Child, D. (2006). The Essentials of Factor Analysis (3rd ed.). New York: Continuum.

Choe, JM. (1998). The effect of user participation on the design of accounting information systems. Information \& Management, 34(3), 185-198. https://doi.org/10.1016/S0378-7206(98)00055-X

Collis, J. \& Hussey, R. (2014) Business research: A practical guide for undergraduate and postgraduate students. 4th ed. London: Palgrave-MacMillan.

Committee of Sponsoring Organizations of the Treadway Commission. (2013). Internal control - integrated framework: $\quad$ Executive $\quad$ summary. $\quad$ Retrieved $19 \quad$ May 2016 from http://www.coso.org/documents/990025P_Executive_Summary_final_may20_e.pdf

Davis, F.D. (1989). Perceived usefulness, perceived ease of use, and user acceptance of information technology. MIS Quarterly, 13(3), pp. 319-340.

Davis, F.D., \& Venkatesh, V. (1996). A critical assessment of potential measurement biases in the technology acceptance model: Three experiments. International Journal of Human-Computer Studies, 45(1), pp.19-45.

DeLone, W. H., \& McLean, E. R. (1992). Information systems success: The quest for the dependent variable. Information Systems Research, 3(1), 60-95. 
DeLone, W. H., \& McLean, E. R. (2003). Information systems success: A ten-year update. Journal of Management Information Systems, 19(4), 9-30. http://doi.org/10.1080/07421222.2003.11045748

Doll, W. J., and Torkzadeh, G. (1998). Developing a multidimensional measure of systems use in an organizational context. Information \& Management, 33(4), 171-185.

Elliott, B., \& Elliott, J. (2013). Financial accounting and reporting. (16th ed.). Harlow, UK: Pearson Education Limited.

Fardinal. (2013). The quality of accounting information and the accounting information system through the internal control systems: A study on Ministry of State Agencies of the Republic of Indonesia. Research Journal of Finance and Accounting, 10(10), 1-14.

Ghasemi, M., Shafeiepour, V., Aslani, M., \& Barvayeh, E. (2011). The impact of information technology (IT) on modern accounting systems. Procedia - Social and Behavioural Sciences, 28, 112-116.

Gliem, J. A., \& Gliem, R. R. (2003, October 8-10). Calculating, interpreting, and reporting Cronbach's alpha reliability coefficient for Likert-type scales [Paper Presentation]. 2003 Midwest Research to Practice Conference in Adult, Continuing, and Community Education, The Ohio State University, Columbus, OH. Retrieved from https://scholarworks.iupui.edu/

Goldberg, L, R., \& Velicer, W. F. (2006). Principles of exploratory factor analysis. In S. Strack (Ed.). Differentiating Normal and Abnormal Personality (2nd ed., pp. 209-237). New York, NY: Springer.

Gupta, D., \& Jain, M. (2017). Impact of cloud accounting on business performance. International Research Journal of Commerce, Arts and Science, 8(12), 321-329.

Hurt, R. L. (2013). Accounting information systems: Basic concepts and current issues (3rd ed). New York, NY: McGraw-Hill/Irwin.

Intuit Inc. (2018). QuickBooks small business user guide: Starting out with QuickBooks online. Intuit Australia. $\begin{array}{llll}\text { Retrieved } & 16 & \text { October } & 2019\end{array}$ https:/quickbooks.intuit.com/content/dam/intuit/quickbooks/i18n/en/Australia/pdf/QuickBooks-SmallBusiness-User-Guide.pdf

Ismail, N. A., \& King, M. (2007). Factors influencing the alignment of accounting information in small and medium sized Malaysian firms. Journal of Information Systems and Small Business, 1(1/2), 1-20.

Itang, A. E. (2017). The impact of computer-based accounting information systems on effectiveness of internal controls in small and medium-sized enterprises in Nigeria (Unpublished master's dissertation). University of Liverpool, Liverpool, United Kingdom.

Kaiser, H. (1960). The application of electronic computers to factor analysis. Educational and Psychological Measurement, 20, 141-151.

Kpolovie, P. J. (2016). Excellent research methods. Johannesburg: Partridge Publishing.

Krejcie, R. V. \& Morgan, D. W. (1970). Determining sample size for research activities. Educational and Psychological Measurement, 30(3), pp. 607-610.

Marivic, A. (2009). Evaluating the security of computerized accounting information systems. An empirical study on Egyptian banking industry, PhD. Thesis. Aberdeen University, UK

Mathiyazhagan, T., \& Nandan, D. (2010). Survey research methods. Media Mimanda, July-September, 34-45. Retrieved from www.academia.edu/37953075/Survey_research_methods

McLeod, R., \& Schell, G. (2006), Management information systems. (10th ed.). New Jersey: Prentice Hall.

Meiryani, M., Susanto, A., \& Sudrajat, J. (2019). The effect of environmental complexity on the quality of accounting information systems: Integration flexibility and complexity dimensions. ICETT 2019: Proceedings of the 2019 5th International Conference on Education and Training Technologies, May 2019, 115-119. https://doi.org/10.1145/3337682.3337702

Mele, C., Pels, J., \& Polese, F. (2010). A brief review of systems theories and their management applications. Service Science, 2(1/2), 126-135.

Muijs, D. (2011). Doing quantitative research in education with SPSS. Los Angeles: Sage Publications

Nulty, D. D. (2008). The adequacy of response rates to online and paper surveys: What can be done? Assessment \& Evaluation in Higher Education, 33(3), 301-314.

Paganini, C. (2019). Primer: Understanding software and system architecture. Online: The New Stack. Retrieved 13 April 2020 from https://thenewstack.io/primer-understanding-software-and-system-architecture/

Qatanani, K. M. \& Hezabr, A. A. (2015). The effect of using accounting information systems to improve the value chain in business organisations - Empirical study. European Journal of Accounting Auditing and Finance Research, 3(6), 1-11. Retrieved 16 May 2016 from http://www.eajournals.org/wpcontent/uploads/The-Effect-of-Using-Accounting-Information-Systems-to-Improve-the-Value-Chain-inBusiness-Organizations-Empirical-Study.pdf

Radhakrishna, R. B. (2007). Tips for developing and testing questionnaires/instruments. Journal of Extension, 45(1), 1-3.

Ramakrishnan, R., \& Gehrke, J. (2003). Database management systems (3rd ed). New York, NY: McGraw-Hill. 
Ramosaj, B., \& Berisha, G. (2014). Systems theory and systems approach to leadership. Iliria International Review, 4(1), 59-76. http://doi.org/10.21113/iir.v4i1.53

Romney, M. B., \& Steinbart, P. J. (2006). Accounting information systems (10 ed.). New Jersey: Pearson Prentice-Hall.

Romney, M. B., \& Steinbart, P. J. (2009). Accounting information systems (11 Ed.). New Jersey: Pearson Prentice-Hall.

Sage Software, Inc. (2015). Sage 50 accounting - US edition: User guide. Sage Software. Retrieved 20 January 2020 from https://cdn.na.sage.com/docs/en/customer/50us/open/Sage50UserGuide.pdf

Sajady, H., Dastgir, M., \& Nejad, H. H. (2008). Evaluation of the effectiveness of accounting information systems. International Journal of Information Science and Technology, 6(2), 49-59.

Salhin, A., kyiu, A., Taheri, B., Porter, C., Valantasis-Kanellos, N., \& Konig, C. (2016). Quantitative data gathering methods and techniques. In A. Paterson, D. Leung, W. Jackson, R. Maclntosh, \& K. O'Gorman (Eds.). Research methods for accounting and finance (pp. 168-186). Oxford: Goodfellow Publishers Limited.

Samuels, P. (2016, June). Advice on exploratory factor analysis. (Working Paper). Centre for Academic Success, Birmingham City University. https://doi.org/10.13140/RG.2.1.5013.9766

Steckel, A. J. (2011). Analysis of QuickBooks internal control utilization (Honours programme thesis, University of Northern Iowa, UNI Scholars Works Retrieved from http://scholarworks.uni.edu/cgi/viewcontent.cgi?article $=1005 \&$ context $=$ hpt

Surendar, G. \& Rathnakar, G. (2019). Accounting profession - Role of information technology. International Journal of Advanced Trends in Computer Science and Engineering, 8(1.2), 154-160.

Thuan, L. D., \& Huong, T. T. T. (2019). Organizational factors and quality of accounting information systems in Vietnam. Global Journal Al-Thaqafah (GJAT), 9(1), 49-58.

Whittington, R., \& Pany, K. (2004). Principles of auditing and other assurance services. (16th ed.). New York, NY: McGraw-Hill/Irwin.

William, B., Onsman, A., \& Brown, T. (2010). Exploratory factor analysis: A five step guide for novices. Journal of Emergency Primary Health Care, 8(3), 1-13.

Zielinski, A. (2015). Preventative and detective fraud controls in accounting software. Online: EisnerAmper Accountants \& Advisors. Retrieved 15 April 2016 from http://www.eisneramper.com/fraud-controlsoftware-1115.aspx

\section{Appendix}

\section{SAMPLE COPY OF \\ COMPUTERIZED ACCOUNTING SYSTEMS MEASUREMENT TOOL ASSESSMENT QUESTIONNAIRE}

\section{INTRODUCTION}

This questionnaire presents a measurement tool developed for the assessment of the quality and effectiveness of computerized accounting systems. The aim of this survey is to collect data for the purpose of testing the validity and reliability of the measurement tool presented. It should be completed by someone performing accounting/finance functions (by whatever title) in your organization. The questionnaire is divided into two sections, namely (A) Firm Demographic Information, and (B) Computerized Accounting System Evaluation. This will take about 20 minutes of your time. Be assured that all information will be kept in strict confidence and used only for the purpose of this study. Note that your participation is voluntary and greatly appreciated.

SECTION A: FIRM DEMOGRAPHIC INFORMATION

In this section you are asked to provide demographic information about your organization.

[FDI1]. What is the legal form of your business organization?
[] Sole-Proprietorship
[] Partnership
[] Family-Owned
[] Private Limited Company

[DI2]. Which of the following economic sectors does your business organization belong?
[] Manufacturing
[] Construction
[] Wholesale/Retail
[] Accommodation/Food Services
[] Agriculture
[] Information/Communication
[] Education
[] Mining/Quarrying/Oil Servicing
[] Arts/Entertainment/Recreation
[] Transportation/Storage
[] Administrative/Support Services
[] Sewage/Waste/Remediation

[] Other Services/Activities

[DI3]. What is your official job title? (Choose the closest title if your direct title is not in the alternatives) 
[] Chief Finance Officer/Financial Controller

[] Finance/Accounts Manager

[] Chief Accountant

[] Accountant/Accounts Officer

[] Auditor

[DI4]. Is your organization's accounting system computerized? [] Yes [] No

SECTION B: COMPUTERIZED ACCOUNTING SYSTEMS EVALUATION

This Section employs Likert-type scales to evaluate/assess the structural characteristics or functional components of your computerized accounting system. You are to indicate the extent to which you agree with each of the statements numbered IC1- ET5 based on the following scale:

$1=$ Strongly disagree

$2=$ Disagree

$3=$ Neutral

$4=$ Agree

$5=$ Strongly agree

Please tick any of the options as appropriate.

Internal Controls:

[IC1]. In our computerized accounting system predefined users only can have access to the system with the use of passwords.
[1] Strongly Disagree
[2] Disagree
[3] Neutral
[4] Agree
[5] Strongly Agree

[IC2]. In our computerized accounting system users are assigned specific roles to ensure segregation of duties.

[1] Strongly Disagree

[2] Disagree

[3] Neutral

[4] Agree

[5] Strongly Agree

[IC3]. Our computerized accounting system checks and confirms the accuracy of data entered in the systems.
[1] Strongly Disagree
[2] Disagree
[3] Neutral
[4] Agree
[5] Strongly Agree

[IC4]. Our computerized accounting system is protected from intrusions, information theft, and data manipulation.
[1] Strongly Disagree
[2] Disagree
[3] Neutral
[4] Agree
[5] Strongly Agree

[IC5]. Our computerized accounting system can provide audit trail on users and transactions.

[1] Strongly disagree

[2] Disagree

[3] Neutral

[4] Agree

[5] Strongly agree

Automated Data Processing:

[AP1]. Our computerized accounting system performs tasks and processes seamlessly.
[1] Strongly Disagree
[2] Disagree
[3] Neutral
[4] Agree
[5] Strongly Agree

[AP2]. Our computerized accounting system has data validation functionalities.

[1] Strongly Disagree

[2] Disagree 

[3] Neutral
[4] Agree
[5] Strongly Agree

[AP3]. Our computerized accounting system performs transactions posting automatically.
[1] Strongly Disagree
[2] Disagree
[3] Neutral
[4] Agree
[5] Strongly Agree

[AP4]. Our computerized accounting system performs accounts balancing functions automatically.
[1] Strongly Disagree
[2] Disagree
[3] Neutral
[4] Agree
[5] Strongly Agree

[P5]. Our computerized accounting system has accounts reconciliation functionality
[1] Strongly Disagree
[2] Disagree
[3] Neutral
[4] Agree
[5] Strongly Agree

Relational Database:

[RD1]. Our computerized accounting system can store large collection of data.
[1] Strongly Disagree
[2] Disagree
[3] Neutral
[4] Agree
[5] Strongly Agree

[RD2]. Our computerized accounting system enhances the maintenance and retrieval of large collections of data.
[1] Strongly Disagree
[2] Disagree
[3] Neutral
[4] Agree
[5] Strongly Agree

[RD3]. Our computerized accounting system ensures the independence and integrity of data.
[1] Strongly Disagree
[2] Disagree
[3] Neutral
[4] Agree
[5] Strongly Agree

[RD4]. Our computerized accounting systems ensures the security, backup, and recovery of data.
[1] Strongly Disagree
[2] Disagree
[3] Neutral
[4] Agree
[5] Strongly Agree

[RD5]. Our computerized accounting system ensures concurrent access to data and information in the system.
[1] Strongly Disagree
[2] Disagree
[3] Neutral
[4] Agree
[5] Strongly Agree

Automated Reporting:

[AR1]. Our computerized accounting system generates financial statements and reports seamlessly.
[1] Strongly Disagree
[2] Disagree
[3] Neutral
[4] Agree
[5] Strongly Agree 
[AR2]. Our computerized accounting systems can generate the Trial balance and other general ledger reports automatically.
[1] Strongly Disagree
[2] Disagree
[3] Neutral
[4] Agree
[5] Strongly Agree

[AR3]. Our computerized accounting system can generate various financial statements (e.g. Income statement, Balance sheet, etc.).
[1] Strongly Disagree
[2] Disagree
[3] Neutral
[4] Agree
[5] Strongly Agree

[AR4]. Financial statements and reports can be generated from our computerized accounting system based in multiple formats and reporting options.
[1] Strongly Disagree
[2] Disagree
[3] Neutral
[4] Agree
[5] Strongly Agree

[AR5]. Our computerized accounting system can generate financial statements with comparative figures.
[1] Strongly Disagree
[2] Disagree
[3] Neutral
[4] Agree
[5] Strongly Agree

Enhancing Technologies:

[ET1]. Our computerized accounting system is (or could be used) on a network.

[1] Strongly Disagree

[2] Disagree

[3] Neutral

[4] Agree

[5] Strongly Agree

[ET2]. Our computerized accounting system is (or could be migrated to) cloud based.
[1] Strongly Disagree
[2] Disagree
[3] Neutral
[4] Agree
[5] Strongly Agree

[ET3]. Our computerized accounting system can interface with Point of Sale (POS) devices.
[1] Strongly Disagree
[2] Disagree
[3] Neutral
[4] Agree
[5] Strongly Agree

[ET4]. Our computerized accounting system supports documents upload and attachments.
[1] Strongly Disagree
[2] Disagree
[3] Neutral
[4] Agree
[5] Strongly Agree

[ET5]. Our computerized accounting system supports Email/SMS facilities.

[1] Strongly Disagree

[2] Disagree

[3] Neutral

[4] Agree

[5] Strongly Agree

THE END! 